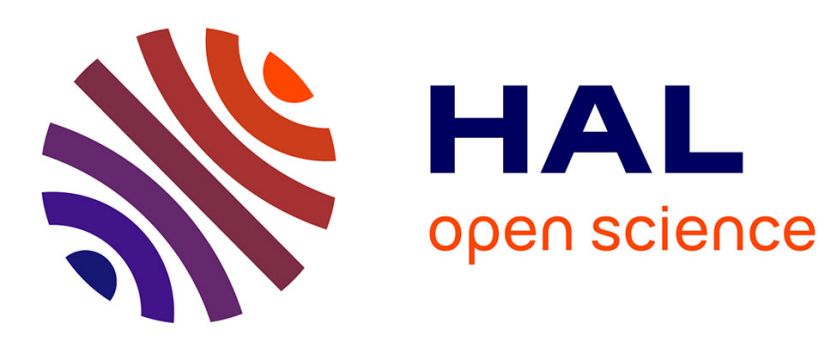

\title{
Cumulative stressors trigger increased vulnerability of diatom communities to additional disturbances
}

Soizic Morin, B. Bonet, N. Corcoll, H. Guasch, M. Bottin, Michel Coste

\section{To cite this version:}

Soizic Morin, B. Bonet, N. Corcoll, H. Guasch, M. Bottin, et al.. Cumulative stressors trigger increased vulnerability of diatom communities to additional disturbances. Microbial ecology, 2015, 70 (3), pp.585-595. 10.1007/s00248-015-0602-y . hal-01229414

\section{HAL Id: hal-01229414 \\ https://hal.science/hal-01229414}

Submitted on 16 Nov 2015

HAL is a multi-disciplinary open access archive for the deposit and dissemination of scientific research documents, whether they are published or not. The documents may come from teaching and research institutions in France or abroad, or from public or private research centers.
L'archive ouverte pluridisciplinaire HAL, est destinée au dépôt et à la diffusion de documents scientifiques de niveau recherche, publiés ou non, émanant des établissements d'enseignement et de recherche français ou étrangers, des laboratoires publics ou privés. 
Cumulative stressors trigger increased vulnerability of diatom communities to additional disturbances.

Soizic Morin ${ }^{1, *}$, Berta Bonet ${ }^{2}$, Natàlia Corcoll ${ }^{2,3}$, Helena Guasch $^{2}$, Marius Bottin ${ }^{1}$, Michel Coste $^{1}$

${ }^{1}$ Irstea, UR EABX. 50 avenue de Verdun, 33612 Cestas cedex, France

${ }^{2}$ Institut d'Ecologia Aquàtica, Universitat de Girona, Campus Montilivi, 17071 Girona, Spain

${ }^{3}$ Department of Biological and Environmental Sciences, University of Gothenburg, Box 461, SE-40530, Gothenburg, Sweden

* Corresponding author: soizic.morin@irstea.fr; telephone: +33557892726

\section{Summary}

Chronic, non-lethal stressors occurring gradually (in space or time) can result in cumulative impacts that are more dramatic than higher intensities or occasional critical levels of any single one of these stressors. The negative effects of the chronic stressors trigger lasting impacts that may grow in intensity and become problematic over time and/or to higher trophic levels.

In rivers, aquatic organisms experience this type of cumulative stress along the up- to downstream gradient in natural and anthropogenic contaminants generally observed in inhabited watersheds. Diatoms are a major component of the periphyton in rivers; their richness and diversity in natural communities are directly related to their varied ecological preferences and sensitivity to disturbance.

In this study, we monitored from 2003 to 2008 the changes in the diversity of taxonomic and non-taxonomic features along a small river (Riou-Mort, South West France), at three sites: one site upstream considered as a reference for this watershed, one intermediate site with high nutrient load, and one downstream site exposed to both nutrient and metal pollution. The cumulative impacts of nutrients plus metals led to a gradual decrease in species richness and diversity, and in a potential capacity to cope with additional stresses, e.g. climate change- 
related ones. This is reflected by a decrease in species richness downstream, more dramatic in the hot summer of 2003 than in cooler summers.

With the increasingly protective environmental regulations (e.g. Water Framework Directive in Europe), accumulation of stresses on aquatic resources are recommended to receive increasing attention, in particular considering the expected changes in climate.

\section{Keywords}

Diatom communities; metals; $\alpha$ - and $\beta$-diversity; vulnerability; microbial ecotoxicology 


\section{Introduction}

Periphyton and, more specifically, diatom communities are often used as "model communities" because they are composed of organisms with short generation times and rapid growth, i.e. with a quick response time, facilitate many species interactions, and form the basis of ecosystem functioning (in particular, photosynthetic processes). These properties mean that they are particularly interesting for environmental studies: they allow the observation, on a relative short time scale, of complex phenomena that are also expected to happen at higher organisational levels (e.g. higher plants) in the longer term.

In periphyton-based risk assessment, the effects of a single contaminant or of mixtures of contaminants on the community are evaluated through structural and/or functional changes. Specifically, acute and chronic (time scale of weeks) exposures can be assessed by considering diverse functional and structural features, respectively [1]. The severity of the impacts can be characterized in terms of consequences, i.e. cost of adaptation to the pollution, for the community [2] . This includes biodiversity estimates, or indicators of reversibility of the impact [e.g. recovery time, 3,4], or loss of tolerance to repeated exposure to the same, or to another, stress factor [5].

In diatom communities with a high level of species diversity, very different stresses piled on top of each other can cause gradual structural changes. These cumulative impacts can lead to a substantial, even irremediable, erosion of the characteristics of the community. River diatoms have recently been shown to be structured into metacommunities [6,7], according to the common definition, i.e. fairly discrete and well-delineated local communities connected by exchanges of individuals (colonisation). In small rivers, many exchanges occur between local communities, and are likely to lead to homogeneous community structures within the metacommunity, all environmental conditions being similar [8]. In contrast, environmental filters [9] of different types, would progressively select for adapted species, as summarized in the conceptual framework in Figure 1. In this framework, we hypothesize that, in a small river where the distances between habitats and sites are short and connectivity maintained, local diatom communities have a high dispersal potential [10,11], combined with numerous local interactions within metacommunities [12]. Thus, we assume that established (mature) communities should be comparable in terms of community composition and traits (defined as particular biological or physiological properties) between close, similar, sites. In contrast, the presence of environmental discontinuities, especially significant chronic contaminations of 
different types, would trigger linear or non-linear decreases in redundancy based on the traits of the species present, by successive selection of taxa resistant to each of the stressors [13]. Along the stretch considered, the accumulation of persistent (but not immediately lethal) contaminations of various types may, each time a new stressor is introduced, act as iterative selection pressures, endangering the ultimate (downstream) community by impacting its structure and function, and thus the resistance potential of the ecosystem to any additional disturbance.

Among the disturbances known to drive diatom community structure, the consequence of increased concentrations of organic and inorganic nutrients has been studied extensively, and classifications based on species adaptation to various levels of trophy and saprobity have been produced [e.g. 14]. Besides, diatom tolerance to metal pollution has received increasing attention, leading to a recent description of species sensitivities [15]. The impacts of cumulative stresses on fluvial biofilms can be experimentally reproduced in laboratory experiments, assessing the single and combined effects of toxicants and light [16-19], phosphorus [20,21], drought [5], etc. In Guasch et al. [20,21], nutrient limitation was shown to enhance copper toxicity to algal biomass, diatom community structure and photosynthetic activity, whereas P-fertilization partially compensated these impacts. Tlili et al. [20,21] confirmed the interaction between copper and phosphate and hypothesized antagonism related to decreased bioavailability by complexation of the metal. Although situations can be found where contaminations of different types occur in situ successively (in space or time), disentangling the responses to multiple stressors is rarely studied from the angle of cumulative selection by the successive stressors. In this context, we hypothesize (Figure 1) that the greater the number of cumulative environmental stressors, the higher the impacts on diatom communities, though some antagonistically-acting stressors have been evidenced in diatoms [22,23]. A decrease in species diversity is expected to finally cause increased vulnerability (i.e. lower resistance) of the community to an accumulation of stressors $[13,24]$.

To test the hypothesis of increased vulnerability as stresses accumulate, we surveyed periphytic diatoms during five summers, at three sites along a small river (Riou Mort, South West France), where different environmental filters (nutrients and metals) become sequentially added from up- to downstream. We expected that nutrient, then nutrient plus metal stress, would affect community composition, diversity/redundancy, and trait distribution. Our dataset was then used to determine specific changes driven along the gradient during the 2003 summer heat wave, in order to highlight an increase in vulnerability 
to any additive stress expected with climate change. Delpla et al. [25] reviewed probable consequences of climate warming on rivers, e.g. drought episodes, rise in water temperatures, oxygen depletion. Impacts on species diversity as well as on the distribution of traits were expected to be stronger downstream in 2003 than in cooler years. Finally, we used complementary samplings in a small tributary of the Riou-Mort where the same stressors appear in reverse order, to question the influence of the order of appearance of stressors on diversity estimates.

Materials and methods

\section{Sampling design}

Three sites were sampled (Firmi, Decazeville and Joanis) along the gradient of nutrient and metal contamination of the Riou-Mort river (Figure 2). The environmental gradient has been extensively described previously [26-28]. In this watershed, the conductivities are extremely high for freshwater (> $1000 \mu \mathrm{S} / \mathrm{cm}$ ), and thus result in a particular environment for the aquatic organisms. Firmi (upstream) is a reference site with well-defined background geochemical characteristics. The intermediate site (6 km downstream), Decazeville, is impacted by urbanization and thus exhibits high nutrient loads. Then $8 \mathrm{~km}$ downstream, at Joanis, metal contamination due to industrial releases [29] is superimposed on the trophic pollution observed in Decazeville. All sites share comparable riparian coverage and river width, but Firmi is partially channelized. Supporting environmental data collected on each occasion of biological material sampling are provided for information in Appendix 1. Land surface temperature anomalies (LSTA) during daytime on the different sampling periods were recovered from http://neo.sci.gsfc.nasa.gov/, and water flows from

http://www.hydro.eaufrance.fr/.

Diatoms were collected as recommended by the standard NF T90-354, i.e. in Summer when the water level is low and the effects of environmental conditions are expected to be greatest, and from natural substrates exposed to comparable fluctuating light conditions [30]. The biofilms grown on at least five pebbles were scraped off and pooled to form one composite sample representative of the assemblage present per site. In this watershed, between-site differences in diatoms were shown to be greater than intra-site variability [28], whatever the period of the year [27]. Therefore, intra site variability was only checked on some occasions 
by taking more than one composite sample per site. Data was collected twice in July and once in August 2003, once in July and August on years 2004 and 2005, and at the very end of June 2007 and 2008 (except for Firmi, not sampled in 2005 and 2008). The diatoms were prepared as recommended by standards NF EN 13946 and NF EN 14407. Identification followed European taxonomic literature [e.g. 31,32].

Additionally, diatom samples from the Riou-Viou stream, a small tributary of the Riou-Mort river, were also collected and identified following the same protocol in Summers 2004, 2005 and 2007. This stream reaches the Riou-Mort river a few hundred meters upstream of the Joanis site. Between Moulin (upstream) and Usine (located just before the confluence with the Riou-Mort river), metal contamination occurs, whereas nutrient inputs remain low [22, Appendix 1]. Then, at Joanis downstream of the confluence, metals are as high as in Usine, but nutrients add up [22]. Riou-Viou species were expected to diverge taxonomically from the ultimate downstream site (Joanis) due to slightly different geochemical backgrounds of the rivers and low contribution in volume to the final drift of species. The Riou-Mort being the main contributor in terms of flow downstream, Joanis is mainly fed by the pool of species from Decazeville. To go beyond intrinsic taxonomic differences between the two rivers [22], diatom community structure was not studied through species composition, but better compared in terms of integrative metrics (species and traits diversity) that do not rely on locally specific taxonomy.

\section{Data analyses}

Ordination based on diatom community structure

Reciprocal averaging [33] was performed with PC-Ord [34] to ordinate all samples according to community composition (based on the species with $>2 \%$ relative abundances in at least one sample) and occurrence of species along the most structuring environmental gradient along the Riou-Mort river.

Trait calculations

Besides species composition some specific traits were computed following van Dam et al. [14] and Morin et al. [15]. Species abundances and their affiliations to the various modalities of traits (based on the literature) were used to derive distributions of traits, in order to analyze 
potential changes in the biology of the communities in relation to local conditions. In particular, we used traits related to organic enrichment [14], metal tolerance [15], and others potentially affected by climate change consequences: moisture preferences and dissolved oxygen requirements [14].The traits used, and their modalities, are listed in Table 1.

Diversity analyses

$\alpha$-diversity was estimated by richness (number of species per sample) within local communities and by Shannon index [35]. For both global community (i.e. species composition) and trait modalities, $\alpha$-diversity indices were calculated. Variations in $\alpha$ diversity indices between sampling sites were examined using ANOVA, followed by post hoc HSD Tukey tests. Calculations of Pearson similarities on diatom community structures between sites and years were used to determine $\beta$-diversity, representing the between-site turnover of species, and species turnover through time, respectively. All these statistical analyses were computed with XLSTAT version 2015.1.02 (@Addinsoft 1995-2014).

Multi-response permutation procedures (MRPP) were used to test for local (sites) and temporal (years) heterogeneity in periphytic diatom community structure (Zimmerman et al. 1985) based on Bray-Curtis distance, using PC-Ord [34].

\section{Results}

\section{General trends in diatom communities}

Reciprocal averaging (Figure 3) revealed differences in species compositions between sites. As expected, the community structure reflected the increase in water quality degradation: the samples were sorted along Axis 1 from up- to downstream. The community structure upstream (Firmi) showed strong dissimilarity with Decazeville and Joanis (with Pearson coefficients of $0.21 \pm 0.03$ and $0.12 \pm 0.01$, respectively), whereas the two latter sites were more similar (Pearson coefficient of $0.47 \pm 0.03$ ).

Diatom assemblages in Firmi were composed mainly of Cyclotella meneghiniana (relative

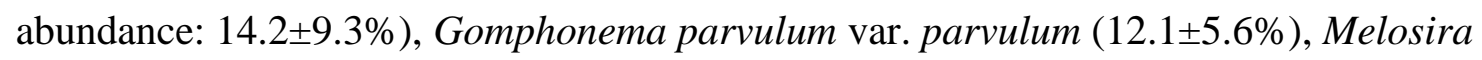

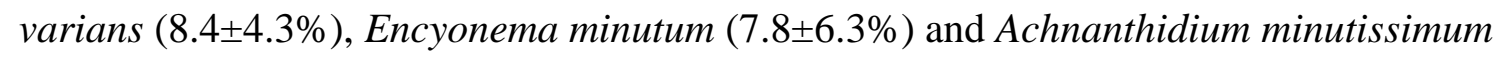
$(7.5 \pm 3.3 \%)$. On Axis 2, high variability in specific composition and higher dissimilarity was found in the reference site expressing the highest variability both between years and within 
local communities (total Pearson similarity of $0.31 \pm 0.05$ between Firmi samples). Changes in dominance between samples were observed at Firmi, with e.g. high abundances of $E$. minutum in $2003(22.3 \pm 20.1 \%)$ or of C. meneghiniana exceeding 60\% in July 2004. The temporal variability and differences in composition decreased along the degradation gradient: lower variability was observable in Axis 2 and similarities within communities were of $0.47 \pm 0.03$ for Decazeville and of $0.75 \pm 0.02$ for Joanis. However, sites always showed coherence in terms of community composition through time (MRPP: $\mathrm{A}=0.281, p<0.0001$ ). At Decazeville, the community was less variable than upstream. High abundances of cosmopolitan species tolerant to trophic pollution were found, like Eolimna minima (20.2 $\pm 5.8 \%)$, Nitzschia palea $(16.5 \pm 3.7 \%)$, C. meneghiniana $(10.7 \pm 4.7 \%)$ or G. parvulum $(7.9 \pm 1.9 \%)$. This change in dominance was accompanied by the disappearance of species with preferences for low nutrient waters like E. minutum, Gomphonema angustatum [32], reflecting the higher nutrient load. Species tolerant to metals dominated in Joanis (e.g. $E$. minima: $47.7 \pm 5.7 \%$, N. palea: $12.0 \pm 3.4 \%$, Pinnularia parvulissima: $5.1 \pm 1.2 \%$ ), as well as percentages higher than $1 \%$ of teratological forms (TRTG) that indicate metal pollution [see reviews by 36,15$]$. In accordance with the environmental conditions at the different sites, the traits related to nutrient enrichment were evenly distributed between $\beta$-mesosaprobous, $\alpha$ mesosaprobous and $\alpha$-meso/polysaprobous at Firmi, whereas the $\alpha$-meso/polysaprobous became dominant at Decazeville and Joanis, due to selection of species adapted to the use of organic material. The proportion of metal-tolerant species increased massively at Joanis (more than $50 \%$ relative abundances, however corresponding only to a few taxa (richness of $c a .3$ ) for the most tolerant modality.

Overall, differences in diatom community composition were higher between years than within years (MRPP: $\mathrm{A}=0.200, p<0.0001$ ). More specifically, taxonomic dissimilarities at Firmi increased with time between samplings of consecutive years (Figure 4). In contrast, at Joanis, assemblages were more similar over time. Samples from Decazeville had intermediate trends between up- and downstream sites, i.e. gradual increase in taxonomic dissimilarity with temporal distance between samples, but intermediate dispersion patterns for samples collected over successive years $(\leq 3)$.

Average $\alpha$-diversity values based on species composition decreased significantly ( $p=0.005$ ) along the up- to downstream gradient (Figure 5a). Richness decreased by $c a$. $30 \%$ between Firmi and Decazeville, then remained stable until Joanis, whereas Shannon values decreased continuously along the gradient, from $2.4 \pm 0.2$ in Firmi down to $1.8 \pm 0.1$ in Joanis. 
Figure 5 indicates different patterns of $\alpha$-diversity along the gradients of the Riou-Mort (Figure 5a) and Riou-Viou (Figure 5b) rivers. Species richness decreased gradually from Moulin (60 \pm 3 species) to Usine, (46 \pm 6$)$ and then Joanis (33 \pm 4$)$, showing successive selection of species. The diversity loss was pronounced between the two first sites, from $3.1 \pm 0.1$ at Moulin to $1.9 \pm 0.2$ at both Usine and Joanis.

\section{Specific impacts of the 2003 heat wave}

Samples were sorted based on species relative abundances according to their site of collection first (Figure 3, Axis 1); then variability along Axis 2 expressed within-site variability. Differences in species composition were more striking upstream (Firmi) and reflected differences between, but also within years. In particular, 2003 samples from Firmi were distributed in the right bottom quarter of Figure 3. During the 2003 heatwave, average land surface temperature anomalies (LSTA) in the area of Decazeville exceeded $6^{\circ} \mathrm{C}$ in July, and $11^{\circ} \mathrm{C}$ in August during daytime. Thus, inter-annual variations in temperature may have led, in addition to species selection, to selection of different traits in periphytic diatoms along the gradient. Consequently, we compared trait distribution in samples collected in summer 2003, to data collected during the cooler summers 2004, 2005, 2007 and 2008 (average LSTA around sampling dates of $-1.4 \pm 1.2^{\circ} \mathrm{C}$ ). No major difference was observed in 2003 neither in water flow compared to other summers, nor in water temperatures at the moment of sampling $\left(22.1 \pm 0.6^{\circ} \mathrm{C}\right.$ vs. $\left.23.1 \pm 0.5^{\circ} \mathrm{C}\right)$. In contrast, dissolved oxygen was significantly reduced $(50.8 \pm 5.1 \%$ vs. $72.3 \pm 6.6 \%$ during cooler years).

Accordingly, diatom traits related to moisture were not affected, which was expectable as no drought was noticed. Diatom oxygen requirements at Firmi did not change much (however almost $30 \%$ of the taxa in 2003 had unknown preferences). In contrast, at Decazeville and Joanis, they differed in 2003, with higher abundances of species tolerating low and very low (10-50\%) oxygen availability.

Few changes in the previously used traits (Figure 6) were noticed at Firmi, but rather occurred downstream (Table 1). At Decazeville and Joanis, the proportion of $\alpha$-mesosaprobous to polysaprobous taxa increased in 2003, expressing increased pollution effects on the community. The higher abundances of Cyclotella meneghiniana at Decazeville in 2003 (tolerant to a wide range of disturbances) subsequently caused a shift towards increased 
tolerance to intermediate metal contaminations. Further downstream, species richness was significantly reduced, with an $\alpha$-diversity loss at Joanis greater than $30 \%$.

\section{Discussion}

Nutrient and metal pollutions drove diatom community composition. Strong changes in community structure occurred between upstream (Firmi) and downstream (Decazeville and Joanis) and expressed the gradient in water quality. These results are in accordance with Passy and Blanchet [37], who reported significantly lower algal $\beta$-diversity with increasing human-mediated degradation of the environment. The variability observed in species composition upstream support the hypothesis of Bottin et al. [6] that diatom community structure and composition in unimpacted sites is mostly environment-driven, whereas other processes (e.g. randomness) affect more impacted communities. Thus, slight temporal or microhabitat changes in conditions in Firmi (temperature, flow, light, etc) may have driven the changes noticed. A higher variability was found in community structure within samples scraped from pebbles of the same reach within the same year (Figure 3), in particular in 2003 and 2004. This heterogeneity may result from the interplay between lower community stability and random dispersion, supporting the idea that processes such as neutrality, dispersal and colonization dynamics might play a role in diatom metacommunities upstream, in addition to the effect of the environment. Conversely, downstream (Decazeville and Joanis) community structures were less variable, in agreement with numerous observations at larger geographical scales demonstrating homogenisation/banalisation of assemblages due to human impact such as eutrophication [38,39]. Indeed, selection by strong environmental drivers (such as, here, nutrient and metal loads) decreases the likelihood for other environmental (abiotic or biotic) factors to additionally force changes in species composition.

The turnover of diatom community composition was rather driven by environmental interannual heterogeneity at Firmi, as shown by the increase in taxonomic dissimilarities with time between samplings (Figure 4). Higher divergence in species distributions over time may denote higher capacity of the upstream communities to adapt to environmental variations. At Joanis, similarities between assemblages were quite constant over time, potentially expressing a reduced inter-annual ability to cope with various additional stressors. This would suggest 
greater vulnerability to new stressors at the downstream site, based on taxonomic distributions. To confirm this hypothesis, the data were further analysed through trait distribution. Cumulative stresses were associated with a progressive decrease in $\alpha$ diversity for both species and traits. Indeed, $\alpha$-diversity based on species composition decreased significantly from Firmi to Joanis (Figure 5a), highlighting a selection simultaneous to the accumulation of stressors. Decreasing species richness with increasing metal loads was already reported by Morin et al. [15]. In the same way, trait distribution was modified along the up- to downstream gradient. Although nutrients, at Decazeville, stimulate biofilm growth [22], species selection occurred, leading to homogenisation of the community between Firmi and Decazeville and impoverishment (in abundances and $\alpha$-diversity) of the oligo- to $\alpha$ mesosaprobous taxa (Figure 6). From Decazeville to Joanis, although species richness remained stable, some metal-tolerant species (E. minima, in particular) became dominant leading to decreased Shannon index values. These results validated our hypothesis of $\alpha$ diversity loss with cumulative stressors. A substantial number of studies have shown a positive relationship between species richness and ecosystem function [40], including in diatom communities [41]. Decreasing $\alpha$-diversity implies a loss of functional redundancy: lower numbers of species with comparable traits (within-trait modalities diversity) reduced the probability of the function being maintained. The communities may thus be more vulnerable to other anthropogenic stressors, including climate change, UV-B radiation, and invasive species [13].

Exposure history modulates the responses of benthic communities to supplementary stressors $[18,5]$. The shift of communities selected by chemicals to alternative stable states however increased their susceptibility to additional disturbances. Here, species and trait selection along the river, in agreement with knowledge about their preferences to nutrient and metal pressures, resulted in community structures different at Firmi, Decazeville and Joanis. Their potential to face an additional stress related to climate change, such as heat wave, was explored by characterizing the distribution of species traits related to moisture and water oxygenation (Figure 5) and further investigated using 2003 data specifically. Over the years, higher abundances of species able to tolerate non-aquatic episodes (wet subaerial species) were found downstream, highlighting that no particular risk of impact caused by drought on diatoms was expected at Joanis. The communities selected by nutrients and metals at this site 
may have reached a stable alternative state [e.g. 42], however based on a reduced pool of species. The downstream community may, thus, have globally increased tolerance to some stressors like decreased water level, but conversely be more vulnerable to other stressors. In particular, sensitivity to oxygen depletion may threaten aquatic organisms in the event of heat wave phenomena, often involving an increase of water temperatures and a decrease in dissolved oxygen saturation [25].The 2003 summertime was the warmest period observed in France since 1950 (source: MeteoFrance, http://www.meteofrance.fr/climat-passe-etfutur/bilans-climatiques/autres-annees/retour-sur-la-canicule-daot-2003-). Oxygen requirements [14] of the communities at Decazeville and Joanis drastically changed towards low/very low oxygen tolerating species (Table 1) in 2003, while upstream communities had balanced proportions in the various oxygen requirement classes. Therefore, the same stressorspecific selection (heat wave) led to a lower range of oxygen optima downstream, where higher vulnerability was thus expectable. These changes could be related to the selection from cumulative stress but also to river morphology: deeper water at Firmi can sustain larger species pools than the riffles downstream (Decazeville and Joanis), as demonstrated by Mullner and Schagerl [43]. The selection of species resistant to various stresses under Decazeville specific conditions (e.g. higher abundances of $C$. meneghinana) caused a shift towards increased tolerance to intermediate metal contaminations in 2003, illustrating indirect selection of traits. As a consequence, the species pool available reaching Joanis was modified. Species richness was reduced by more than $30 \%$ downstream compared to cooler years, suggesting that the 2003 heat wave exacerbated $\boldsymbol{\alpha}$-diversity loss at Joanis.

Together, these environmental and chemical stressors exerted a selection where species were probably not at their prevailing conditions but rather close to their environmental tolerance limits. Multiple disturbances often have non-additive effects and provoke non-linear shifts, where a superimposed disturbance on the community already subject to chemical stress, may cause unexpected or unpredictable alternative ecological states [42]. Under these conditions, a stress considered as sublethal for species living at their optimum may become lethal for species in marginal fringes of their distributions [44]. Since low species diversity implies low functional redundancy, our results suggest that the combination of chemical and natural stressors have inconsistent, strong effects on community structure and trait distribution in ecosystems affected by high anthropogenic impacts. 
Our results highlighted successive selection of species and traits with nutrients first, then nutrients plus metals. Both stressors, acting cumulatively downstream, led to the final community structure at Joanis. In particular, the differences between sites were evident when comparing community structure (Figure 3), and integrative metrics (diversity values) slightly attenuated the amplitude of the response observed, although still significant (Figure 5). Between up- and downstream, each new stress selected taxa adapted to the new environmental conditions: species selected at Decazeville were saprophilous taxa with intermediate growth rates. Metal inputs downstream acted as a supplementary stress, and caused a clear loss in biodiversity and redundancy. These stressors, which pile up in a given order, drove the patterns observed (in species and trait diversity) along the Riou-Mort gradient. However, the order of appearance of stressors of different natures might influence the responses of the final community, simply by selecting, first, a pool of saprobous species, of which metal sensitive species are ultimately replaced by tolerant opportunistic species [45]. Thus, the impacts on diversity downstream might have differed totally if the consecutive species selections had differed, e.g. if they had faced metal contamination first, then nutrient inputs. Data from the Riou-Viou stream provided elements to assess whether the order of appearance of the stressors matters. This tributary of the Riou-Mort river exhibits quite the opposite gradient of stressors (metals followed by nutrient inputs). The changes in water quality observed between upstream and the intermediate site along the Riou-Viou are an increase in metal loads associated with higher mineralization, thus changes in diatom communities were not solely driven by metal contamination. The erosion in diversity at Usine, indeed, accounts for both determinants, that may act synergistically or antagonistically. However, the comparison of $\alpha$-diversity data from the Riou-Mort and Riou-Viou rivers further downstream suggests that metal pollution exerted the strongest pressure on species distribution with extremely marked dominance of a few tolerant species (decrease in Shannon index values). The evolutionary species pool hypothesis [46] links habitat commonness through space and time to potential species richness: the more common the disturbance, the higher the size of the pool of suitably adapted species. In accordance, species pools associated to contemporary disturbances that have been rare through time, such as contaminations of the Anthropocene (comparatively to nutrient fertile habitats), represent a lower number of species. The sharp, metal-driven, decrease in Shannon values reflects serious selection whatever the order of the stressors. Our results confirm this theory, metal contamination (at historically recent levels) acting as the major driving force on diversity. Specifically targeted 
investigations are required to further assess the responses linked to the order of stressors faced.

\section{Conclusions}

Cumulative stress was shown to cause an erosion in $\alpha$ - and $\beta$-diversity. Communities downstream were simplified and dominated by a small number of rather metal-tolerant species but possibly sensitive to additional stress. Moreover, our results suggest that the nature of the stressors imported more than their order, especially in the case of disturbances with variable historical commonness [species pool hypothesis, 46]. This five-year monitoring survey allowed us to assess whether an additional stress (here heatwave) may modify community responses. Increasing vulnerability of already-impacted communities to this additional stress was verified using the data of Summer 2003, where $\alpha$-diversity drastically deceased downstream (ca. 30\%).

Our results are complementary to multistress studies, and provide new insights about successive selection processes exerted along a gradient of cumulative contaminations of different natures. In such environments, climate change pressures may result in unexpected impacts; environmental policies (such as the European Water Framework Directive) should especially focus on these vulnerable habitats.

\section{Acknowledgements}

This study was partially funded by the ANR International program TWIN RIVERS (ANR-11IS56-0003). The authors are grateful to the chemistry laboratories of Irstea (M. Boudigues and M. Bonnet), TGM (UMR EPOC), and Serveis Tècnics de Recerca of the University of Girona for their precious help in analyzing metal concentrations in water. 
1. Sabater S, Guasch H, Ricart M, Romaní A, Vidal G, Klünder C, Schmitt-Jansen M (2007) Monitoring the effect of chemicals on biological communities. The biofilm as an interface. Anal Bioanal Chem 387 (4):1425-1434

2. Tlili A, Maréchal M, Bérard A, Volat B, Montuelle B (2011) Enhanced co-tolerance and co-sensitivity from long-term metal exposures of heterotrophic and autotrophic components of fluvial biofilms. Sci Total Environ 409 (20):4335-4343

3. Laviale M, Morin S, Créach A (2011) Short term recovery of periphyton photosynthesis after pulse exposition to the photosystem II inhibitors atrazine and isoproturon. Chemosphere 84 (5):731-734

4. Morin S, Pesce S, Tlili A, Coste M, Montuelle B (2010) Recovery potential of periphytic communities in a river impacted by a vineyard watershed. Ecol Indicators 10 (2):419426

5. Proia L, Vilches C, Boninneau C, Kantiani L, Farré M, Romaní AM, Sabater S, Guasch H (2013) Drought episode modulates the response of river biofilms to triclosan. Aquat Toxicol 127:36-45

6. Bottin M, Soininen J, Ferreol M, Tison-Rosebery J (2014) Do spatial patterns of benthic diatom assemblages vary across regions and years? Freshwater Science 33 (2):402-416 7. Tornés E, Ruhí A (2013) Flow intermittency decreases nestedness and specialisation of diatom communities in Mediterranean rivers. Freshwat Biol 58 (12):2555-2566. doi:10.1111/fwb.12232

8. Finlay BJ (2002) Global dispersal of free-living microbial eukaryote species. Science 296 (5570):1061-1063. doi:10.1126/science.1070710

9. Lortie CJ, Brooker RW, Choler P, Kikvidze Z, Michalet R, Pugnaire FI, Callaway RM (2004) Rethinking plant community theory. Oikos 107 (2):433-438

10. Morin S, Lambert A-S, Artigas J, Coquery M, Pesce S (2012) Diatom immigration drives biofilm recovery after chronic copper exposure. Freshwat Biol 57 (8):1658-1666. doi:10.1111/j.1365-2427.2012.02827.x

11. Stevenson RJ, Peterson CG (1991) Emigration and immigration can be important determinants of benthic diatom assemblages in streams. Freshwat Biol 26 (2):279-294 12. Verleyen E, Vyverman W, Sterken M, Hodgson DA, De Wever A, Juggins S, Van de Vijver B, Jones VJ, Vanormelingen P, Roberts D, Flower R, Kilroy C, Souffreau C, Sabbe K (2009) The importance of dispersal related and local factors in shaping the taxonomic structure of diatom metacommunities. Oikos 118 (8):1239-1249. doi:10.1111/j.16000706.2009.17575.x

13. Clements WH, Rohr JR (2009) Community responses to contaminants: Using basic ecological principles to predict ecotoxicological effects. Environ Toxicol Chem 28 (9):1789-1800. doi:10.1897/09-140.1

14. van Dam H, Mertens A, Sinkeldam J (1994) A coded checklist and ecological indicator values of freshwater diatoms from the Netherlands. Neth J Aquat Ecol 28 (1):117-133 15. Morin S, Cordonier A, Lavoie I, Arini A, Blanco S, Duong TT, Tornés E, Bonet B, Corcoll N, Faggiano L, Laviale M, Pérès F, Becares E, Coste M, Feurtet-Mazel A, Fortin C, Guasch H, Sabater S (2012) Consistency in diatom response to metal-contaminated environments. In: Guasch H, Ginebreda A, Geiszinger A (eds) Handbook of Environmental Chemistry, vol 19. vol Emerging and Priority Pollutants in Rivers. Springer, Heidelberg, pp 117-146. doi:http://dx.doi.org/10.1007/978-3-642-25722-3 5 16. Kashian DR, Zuellig RE, Mitchell KA, Clements WH (2007) The cost of tolerance: Sensitivity of stream benthic communities to UV-B and metals. Ecol Appl 17 (2):365375. doi:10.2307/40061863 
17. Corcoll N, Bonet B, Leira M, Montuelle B, Tlili A, Guasch H (2012) Light history influences the response of fluvial biofilms to Zn exposure. J Phycol 48 (6):1411-1423. doi:10.1111/j.1529-8817.2012.01223.x

18. Bonnineau C, Sague I, Urrea G, Guasch H (2012) Light history modulates antioxidant and photosynthetic responses of biofilms to both natural (light) and chemical (herbicides) stressors. Ecotoxicology 21 (4):1208-1224. doi:10.1007/s10646-012-08765

19. Laviale M, Prygiel J, Créach A (2010) Light modulated toxicity of isoproturon toward natural stream periphyton photosynthesis: A comparison between constant and dynamic light conditions. Aquat Toxicol 97 (4):334-342

20. Guasch H, Navarro E, Serra A, Sabater S (2004) Phosphate limitation influences the sensitivity to copper in periphytic algae. Freshwat Biol 49 (4):463-473

21. Tlili A, Bérard A, Roulier J-L, Volat B, Montuelle B (2010) $\mathrm{PO}_{4}{ }^{3-}$ dependence of the tolerance of autotrophic and heterotrophic biofilm communities to copper and diuron. Aquat Toxicol 98 (2):165-177

22. Morin S, Duong TT, Boutry S, Coste M (2008) Modulation de la toxicité des métaux vis-à-vis du développement des biofilms de cours d'eau (bassin versant de Decazeville, France). Cryptog Algol 29 (3):201-216

23. Serra A, Guasch H, Admiraal W, Van der Geest H, Van Beusekom SAM (2010) Influence of phosphorus on copper sensitivity of fluvial periphyton: the role of chemical, physiological and community-related factors. Ecotoxicology 19 (4):770-780

24. Yachi S, Loreau M (1999) Biodiversity and ecosystem productivity in a fluctuating environment: The insurance hypothesis. Proceedings of the National Academy of Sciences 96 (4):1463-1468. doi:10.1073/pnas.96.4.1463

25. Delpla I, Jung AV, Baures E, Clement M, Thomas O (2009) Impacts of climate change on surface water quality in relation to drinking water production. Environ Int 35

(8):1225-1233

26. Arini A, Feurtet-Mazel A, Morin S, Maury-Brachet R, Coste M, Delmas F (2012)

Remediation of a watershed contaminated by heavy metals: a 2-year field biomonitoring of periphytic biofilms. Sci Total Environ 425:242-253.

doi:http://dx.doi.org/10.1016/j.scitotenv.2012.02.067

27. Duong TT, Morin S, Herlory O, Feurtet-Mazel A, Coste M, Boudou A (2008) Seasonal effects of cadmium accumulation in periphytic diatom communities of freshwater biofilms. Aquat Toxicol 90 (1):19-28.

doi:http://dx.doi.org/10.1016/j.aquatox.2008.07.012

28. Morin S, Vivas-Nogues M, Duong TT, Boudou A, Coste M, Delmas F (2007) Dynamics of benthic diatom colonization in a cadmium/zinc-polluted river (Riou-Mort, France).

Fundam Appl Limnol 168 (2):179-187. doi:http://dx.doi.org/10.1127/18639135/2007/0168-0179

29. Blanc G, Lapaquellerie Y, Maillet N, Anschutz P (1999) A cadmium budget for the LotGaronne fluvial system (France). Hydrobiologia 410:331-341

30. Bonet B (2013) Antioxidant enzyme activities in fluvial biofilms as biomarkers of metal pollution PhD thesis - Universitat de Girona, Spain

31. Hofmann G, Werum M, Lange-Bertalot H (2011) Diatomeen in Süßwasser-Benthos von Mitteleuropa. A. R. G. Gantner Verlag Kommanditgesellschaft, Rugell

32. Krammer K, Lange-Bertalot H (1986 - 1991) Bacillariophyceae 1. Teil: Naviculaceae. 876 p.; 2. Teil: Bacillariaceae, Epithemiaceae, Surirellaceae, 596 p.; 3. Teil: Centrales, Fragilariaceae, Eunotiaceae, 576 p.; 4. Teil: Achnanthaceae. Kritische Ergänzungen zu 
Navicula (Lineolatae) und Gomphonema. 437 p., vol Band 2/1-4. Süßwasserflora von Mitteleuropa. G. Fischer Verlag., Stuttgart

33. Gauch HG (1977) ORDIFLEX-A flexible computer program for four ordination techniques/ weighted averages, polar ordination, principal components analysis, and reciprocal averaging. Release B. Ecology and Systematics. Cornell University, Ithaca, New York.,

34. McCune B, Mefford MJ (1999) Multivariate analysis of ecological data, version 4.01. MJM Software, Gleneden Beach, Oregon USA,

35. Shannon CE, Weaver W (1949) The mathematical theory of communication. Univ.Illinois Press.Urbana U.S.A. Univ.Illinois Press.Urbana III., 36. Falasco E, Bona F, Badino G, Hoffmann L, Ector L (2009) Diatom teratological forms and environmental alterations: a review. Hydrobiologia 623 (1):1-35. doi:http://dx.doi.org/10.1007/s10750-008-9687-3

37. Passy SI, Blanchet FG (2007) Algal communities in human-impacted stream ecosystems suffer beta-diversity decline. Diversity and Distributions 13 (6):670-679. doi:10.1111/j.1472-4642.2007.00361.x

38. Donohue I, Jackson AL, Pusch MT, Irvine K (2009) Nutrient enrichment homogenizes lake benthic assemblages at local and regional scales. Ecol Lett 90:3470-3477 39. Tison J, Park YS, Coste M, Wasson JG, Ector L, Rimet F, Delmas F (2005) Typology of diatom communities and the influence of hydro-ecoregions: A study on the French hydrosystem scale. Water Res 39 (14):3177-3188

40. Hooper DU, Chapin FS, Ewel JJ, Hector A, Inchausti P, Lavorel S, Lawton JH, Lodge DM, Loreau M, Naeem S, Schmid B, Setälä H, Symstad AJ, Vandermeer J, Wardle DA (2005) Effects of biodiversity on ecosystem functioning: A consensus of current knowledge. Ecol Monogr 75 (1):3-35. doi:10.1890/04-0922

41. Vogt RJ, Beisner BE, Prairie YT (2010) Functional diversity is positively associated with biomass for lake diatoms. Freshwat Biol 55 (8):1636-1646. doi:10.1111/j.13652427.2010.02397.x

42. Scheffer M, Carpenter S, Foley JA, Folke C, Walker B (2001) Catastrophic shifts in ecosystems. Nature 413 (6856):591-596

43. Müllner AN, Schagerl M (2003) Abundance and Vertical Distribution of the Phytobenthic Community within a Pool and Riffle Sequence of an Alpine Gravel Stream. Int Rev Hydrobiol 88 (3-4):243-254. doi:10.1002/iroh.200390022

44. Hummel H, Sokolowski A, Hummel C, Wijnhoven S (2011) Tolerance to natural environmental change and the effect of added chemical stress. In: Amiard-Triquet C, Rainbow PS, Roméo M (eds) Tolerance to Environmental Contaminants. CRC Press, pp 109-124

45. Howarth RW (1991) Comparative responses of aquatic ecosystems to toxic chemical stress. In: Cole J, Lovett G, Findlay S (eds) Comparative Analysis of Ecosystems: Patterns, Mechanisms and Theories. Springer, New York, pp 169-196

46. Aarssen LW, Schamp BS (2002) Predicting distributions of species richness and species size in regional floras: Applying the species pool hypothesis to the habitat templet model. Perspect Plant Ecol Evol Syst 5 (1):3-12

47. Lecointe C, Coste M, Prygiel J (1993) Omnidia - Software for taxonomy, calculation of diatom indices and inventories management. Hydrobiologia 269/270:509-513

48. Coynel A, Schäfer J, Dabrin A, Girardot N, Blanc G (2007) Groundwater contributions to metal transport in a small river affected by mining and smelting waste. Water Res 41 (15):3420-3428 
49. Bonet B, Corcoll N, Tlili A, Morin S, Guasch H (2014) Antioxidant enzyme activities in biofilms as biomarker of $\mathrm{Zn}$ pollution in a natural system: An active bio-monitoring study. Ecotoxicol Environ Saf 103:82-90.

doi:http://dx.doi.org/10.1016/j.ecoenv.2013.11.007 
Table

Table 1. Comparison of $\alpha$-diversity values and traits distribution between the 2003 Summer heat wave and cooler years, along the Riou-Mort gradient (2004-2008).

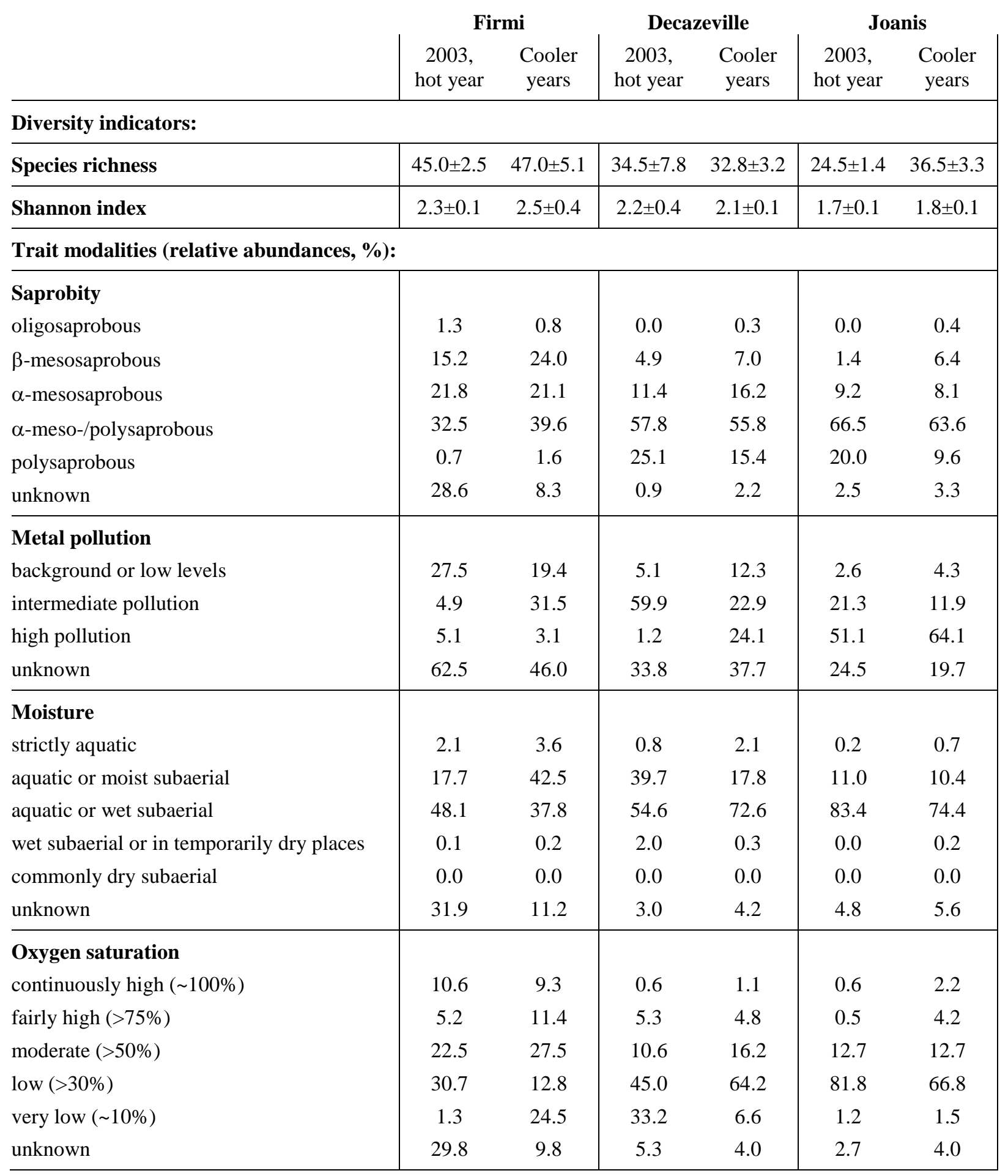


Figure legends

Figure 1. Conceptual framework: Patterns of species distribution, abundance and interactions between local communities (circles) at each site: community patches interact locally and colonise downstream sites, communities are expected to be similar when no significant difference in environmental conditions is observed (A), whereas environmental filters may select for certain species and not others (B), likely to lead to a loss of structural and/or functional diversity.

Figure 2. Location of the study sites. Plain circles: sites located along the main gradient (Riou-Mort river); dashed circles: complementary sites on the Riou-Viou river.

Figure 3. Reciprocal Averaging of the samples based on species distributions. Left panel: samples, in white for Firmi, grey for Decazeville and black for Joanis, labelled by year. Triangles represent real samples ordination, and diamonds average position calculated by site. Right panel: diatom species codes from Omnidia [47], version 5.5 .

Figure 4. Representation of community dissimilarities between samples (Y-axis, measured by the Bray-Curtis coefficient of dissimilarities) and over time (in years, $\mathrm{X}$-axis). Temporal distances were rounded to the year. White symbols represent samples from Firmi, grey ones from Decazeville and black ones from Joanis.

Figure 5. Species richness (grey bars) and Shannon index values (black bars) along a) the Riou-Mort gradient (years 2003, 2004, 2005, 2007, 2008), b) the Riou-Viou gradient (years 2004, 2005, 2007). Values are mean \pm SE. Stars indicate significant differences with upstream site.

Figure 6. Patterns in distribution of traits based on species preferenda/tolerances to nutrient enrichment, metal pollution, drought and water oxygenation, based on species relative abundances (pie charts) and species richness in each trait modality $(\mathrm{R}=$ mean $\pm \mathrm{SE})$. 
A. Close sites, sharing similar environmental conditions

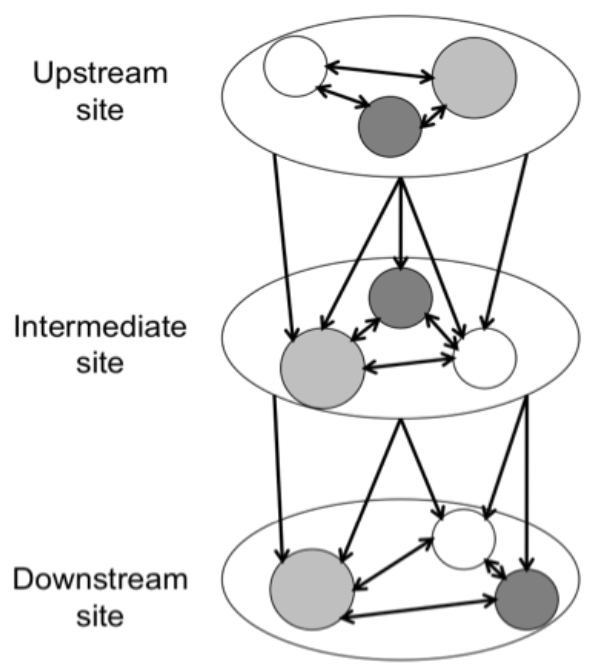

B. Close sites, superimposed stress along the river

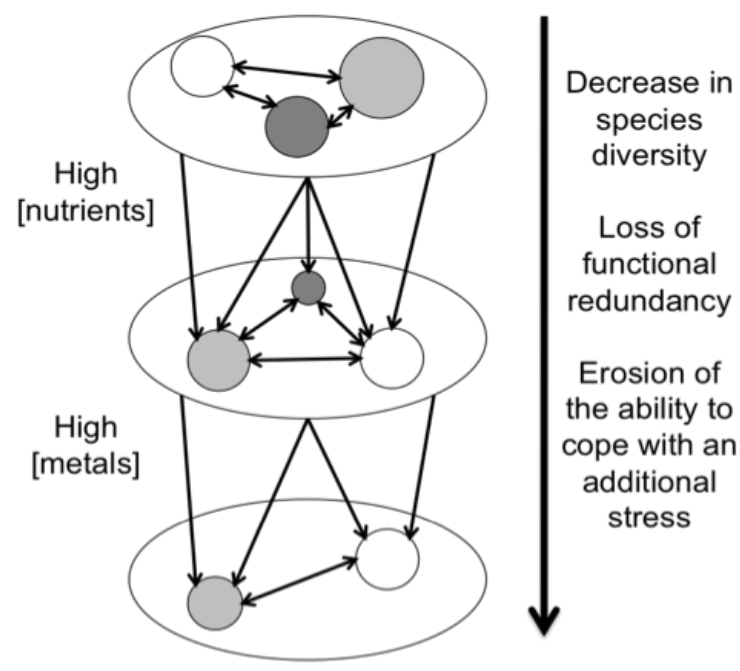

$\longrightarrow$ Species immigration

$\longleftrightarrow$ Species exchanges between metacommunities

Fig 1. 


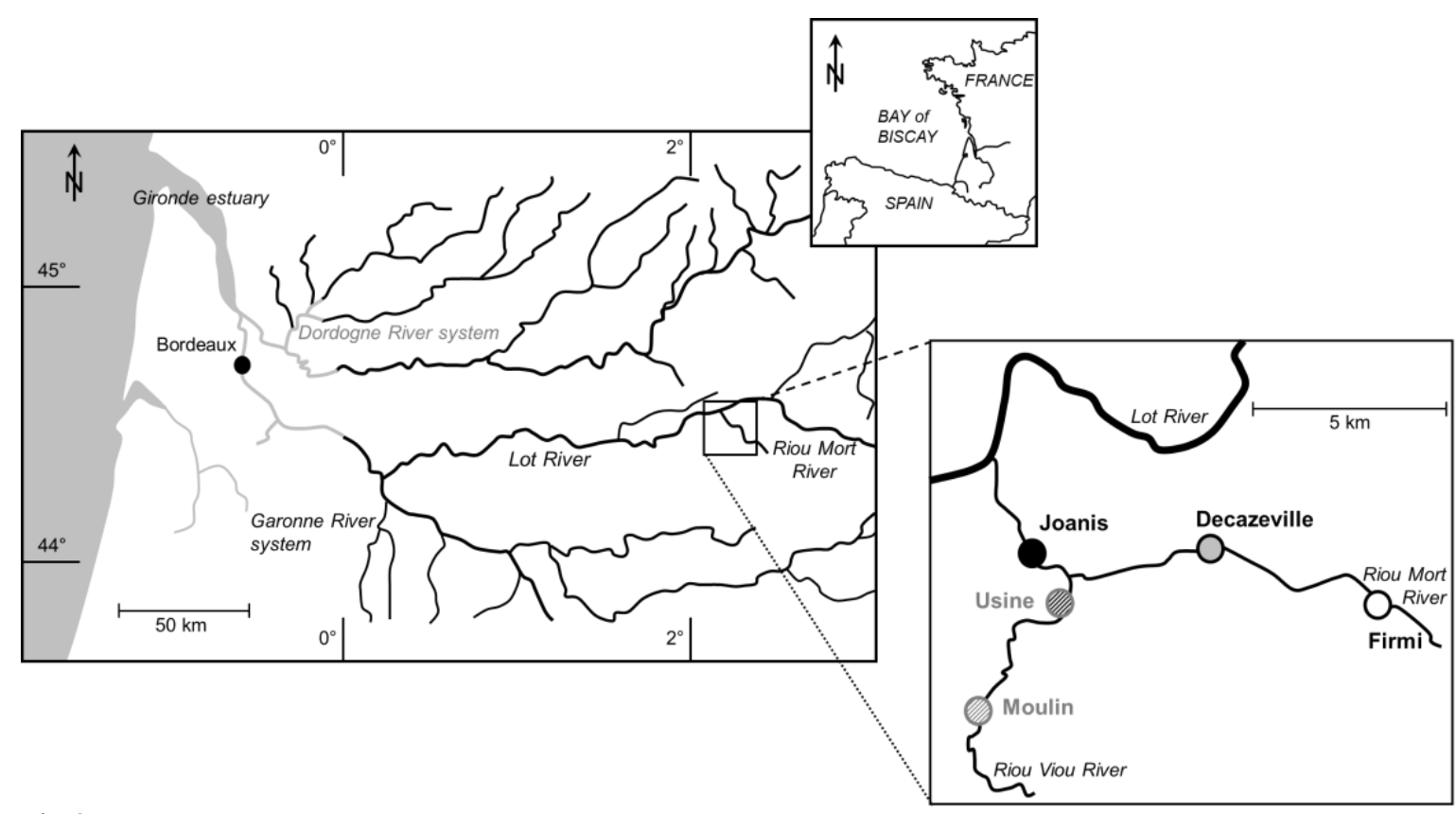

Fig 2. 
Author-produced version of the article published in Microb Ecol (2015) 70: 585-595

The original publication is available at http://link.springer.com/

doi : 10.1007/s00248-015-0602-y

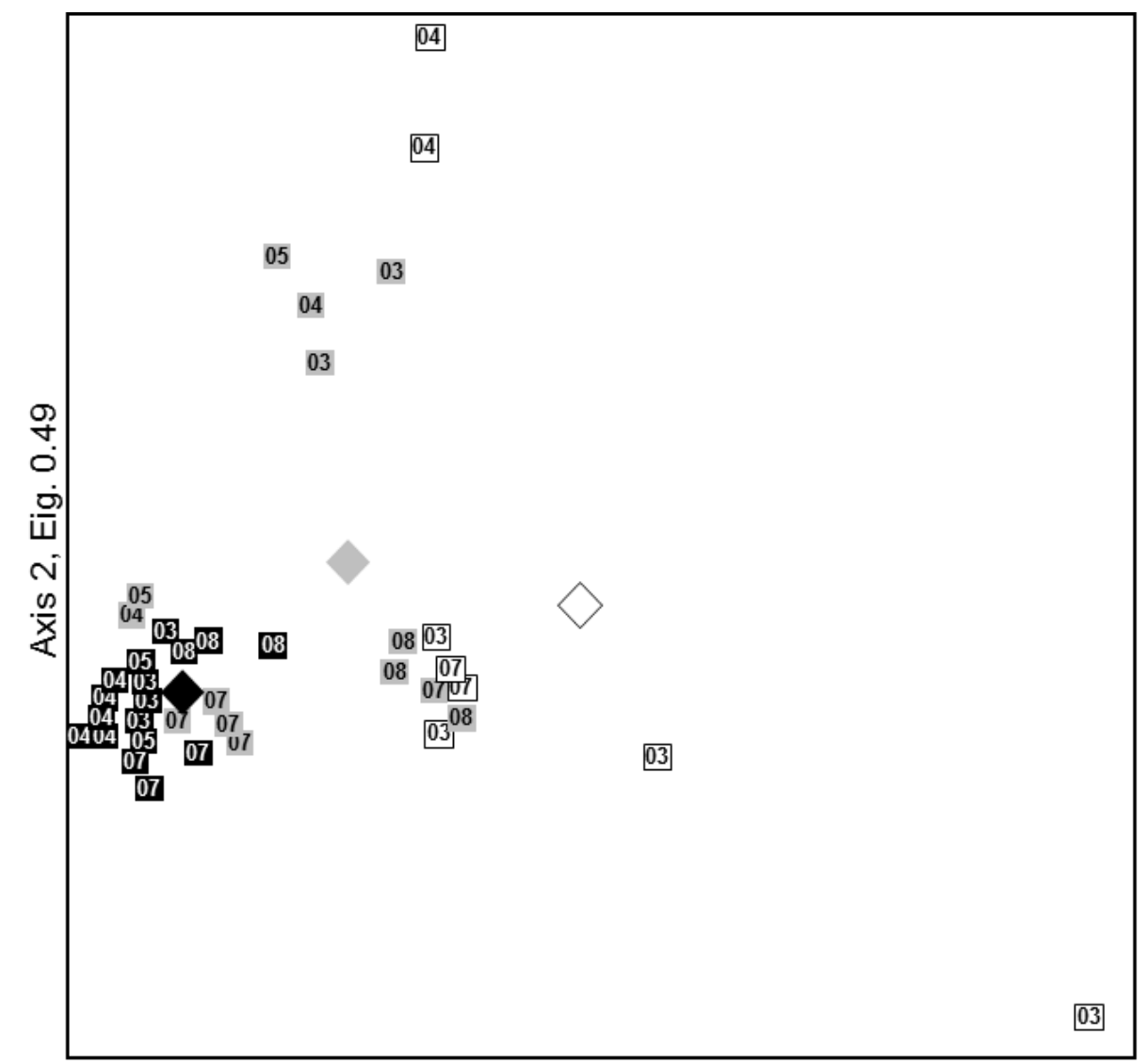

Axis 1, Eig. 0.52

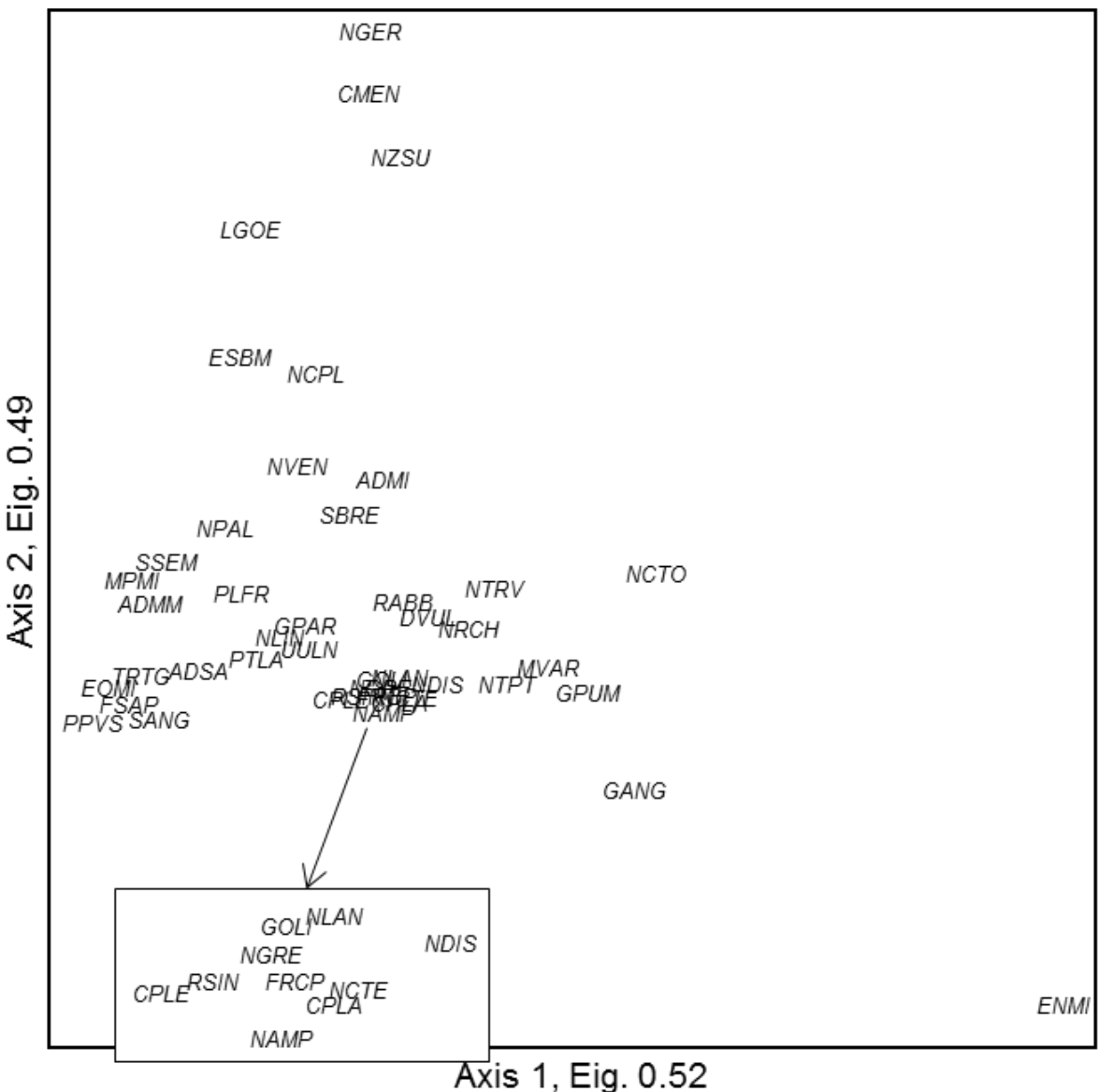

Axis 1, Eig. 0.52

Fig 3. 
The original publication is available at http://link.springer.com/

doi : 10.1007/s00248-015-0602-y
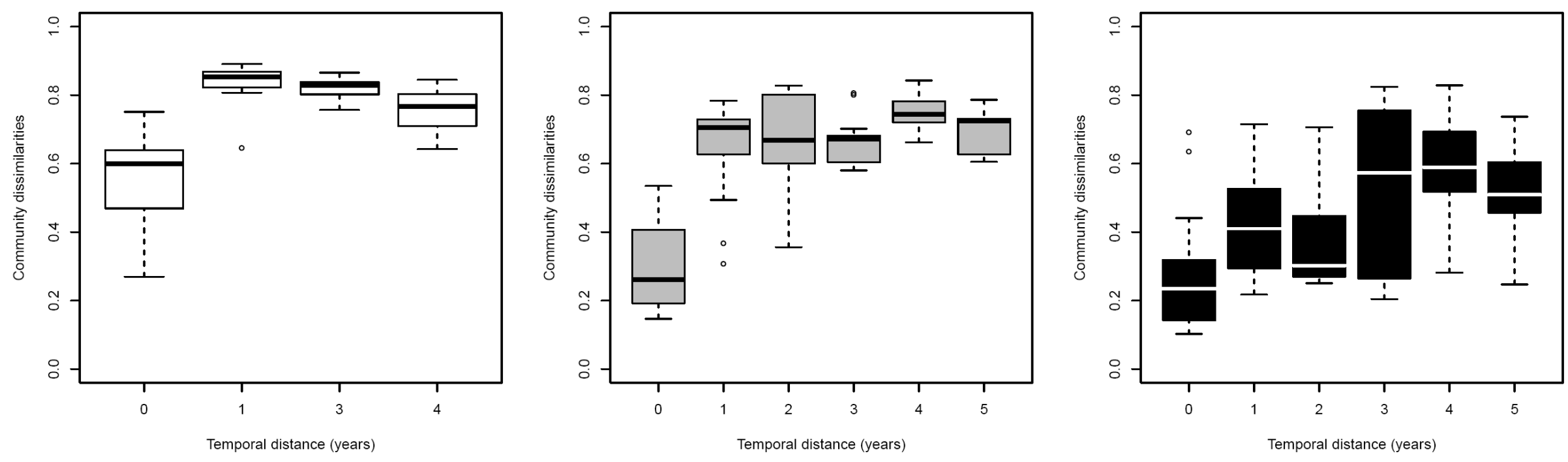

Fig. 4 


\section{doi : 10.1007/s00248-015-0602-y}

a)

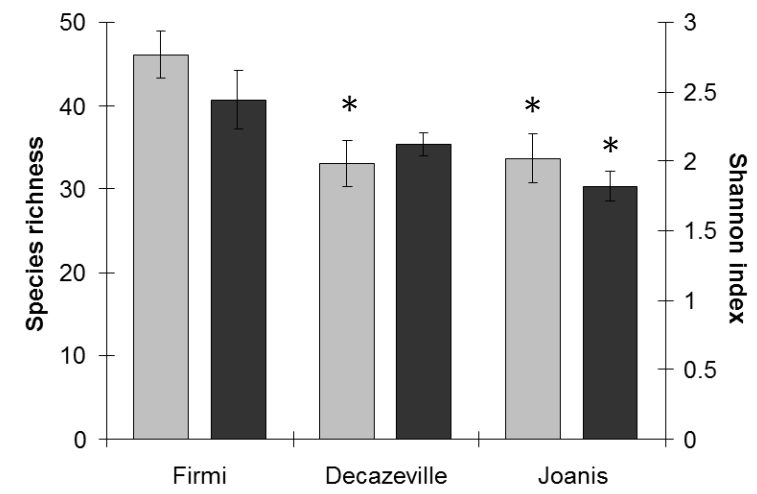

b)

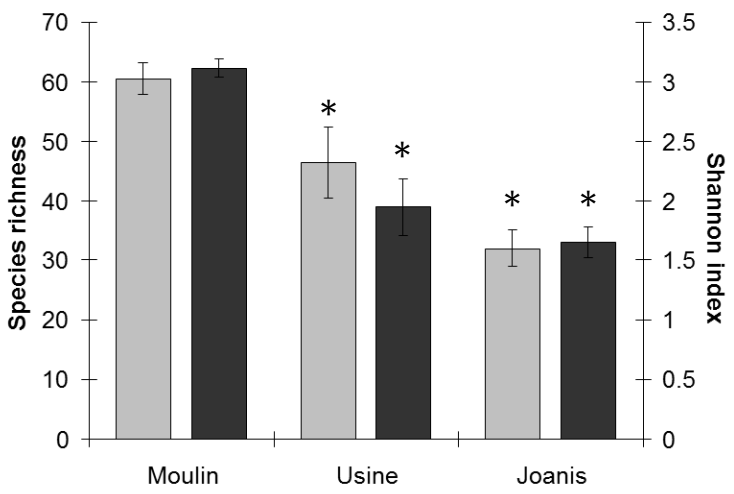

Fig 5. 


$$
\text { doi : 10.1007/s00248-015-0602-y }
$$

Organic enrichmentrelated traits

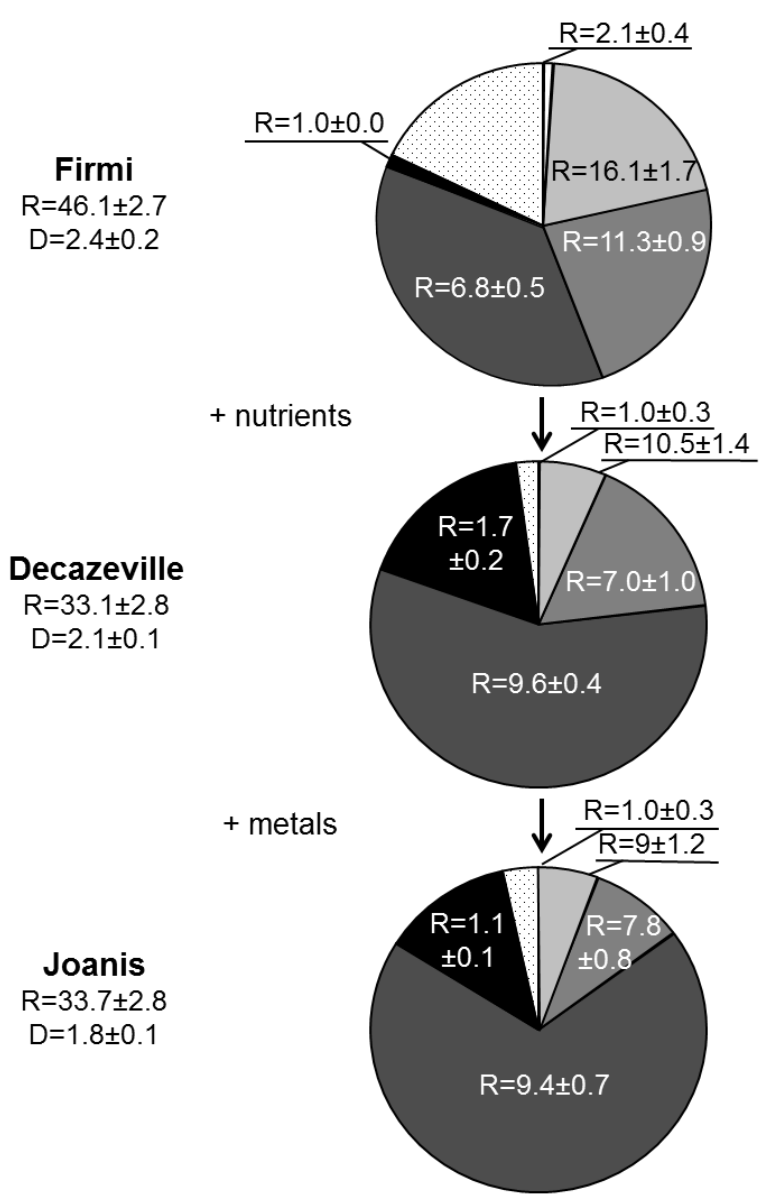

\section{Saprobity}

$\square$ oligosaprobous

B-mesosaprobous

$\alpha$-mesosaprobous

$\alpha$-meso-/polysaprobous

polysaprobous

unknown
Metal tolerancerelated traits

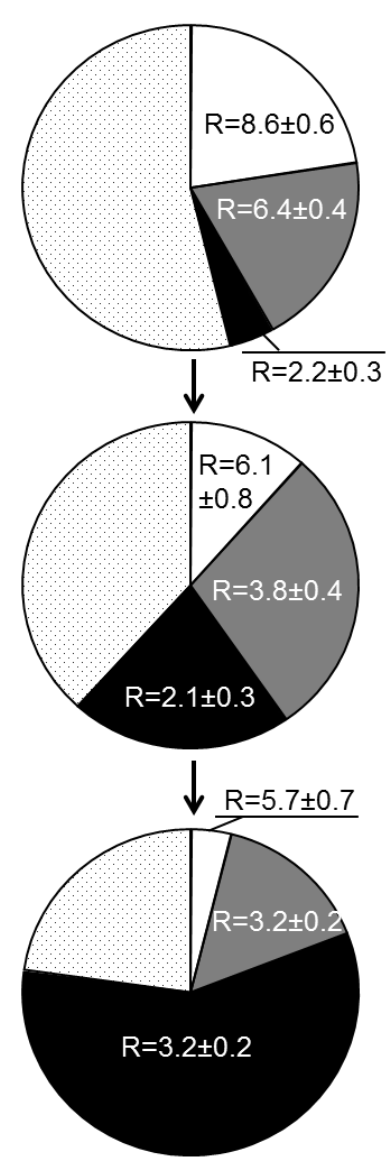

Metal pollution tolerance

$\square$ background or low levels

$\square$ intermediate pollution

high pollution

unknown

Fig 6.

Drought resistancerelated traits

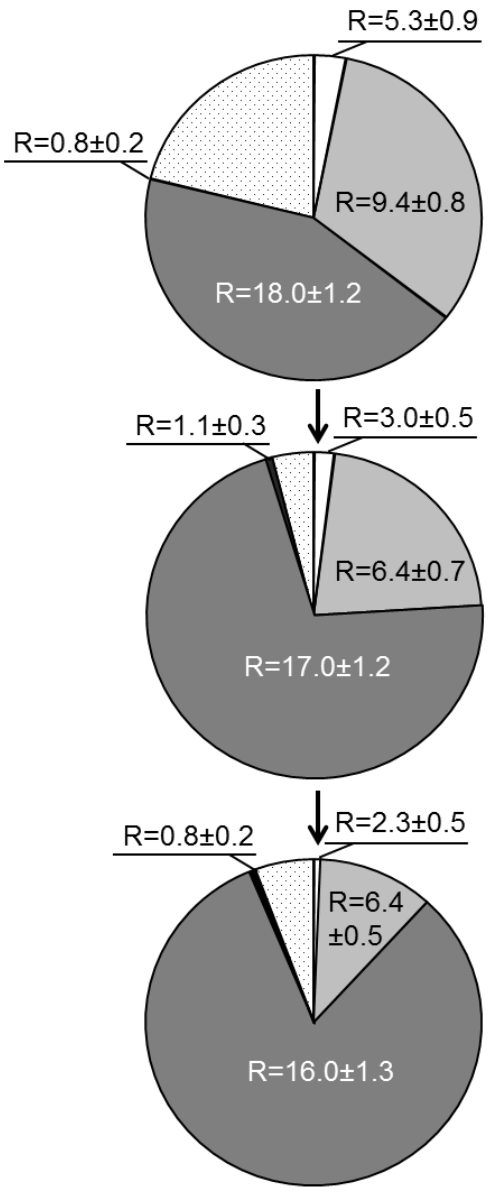

\section{Moisture}

$\square$ strictly aquatic

$\square$ aquatic or moist subaerial

aquatic or wet subaerial

wet subaerial or in

temporarily dry places

commonly dry subaerial

unknown
Oxygen requirementsrelated traits

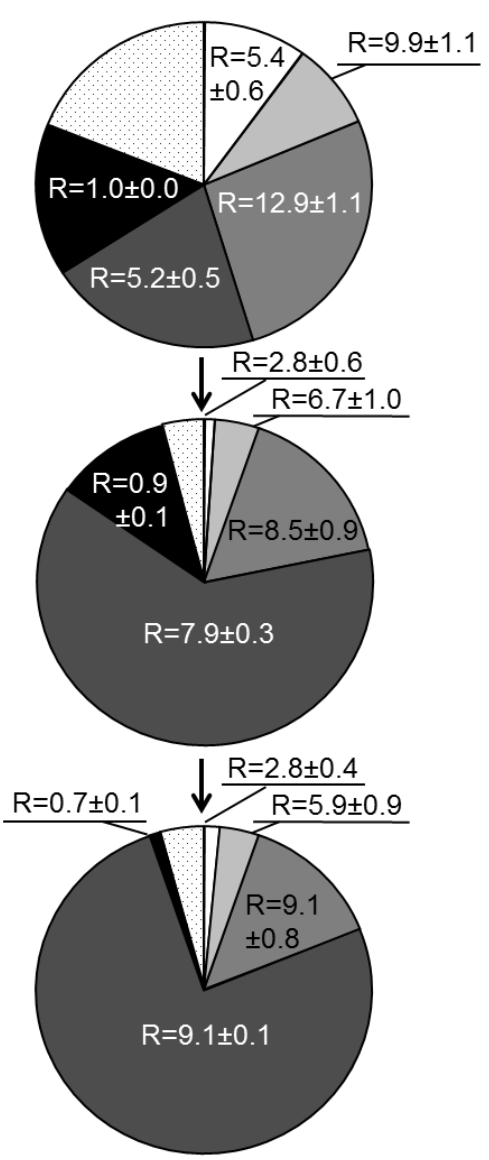

\section{Oxygen saturation}

$\square$ continuously high ( 100\%)

fairly high $(>75 \%)$

moderate $(>50 \%)$

low $(>30 \%)$

very low $(\sim 10 \%)$

unknown 
Appendix 1. Supporting environmental data

Water physicochemical characteristics were determined at each site and on each sampling occasion using appropriate probes (WTW, Weilheim, Germany). Stream water samples were simultaneously collected and brought back to the laboratory for nutrient measurements. Nutrient concentrations were determined according to French and international standards (NF T90-023, NF EN ISO 11732 and NF EN ISO 13395). Mineral nitrogen corresponds to the sum of the different N forms (ammonia, nitrates and nitrites). Dissolved metals (cadmium and zinc) were analysed according to Coynel et al. [48] by the TGM laboratory, University Bordeaux 1, for years 2003 to 2005, and following Bonet et al. [49] in 2007 and 2008.

Table. Main environmental parameters: Mean water characteristics at the times of sampling, and distance to the downstream site. *: not measured in 2003.

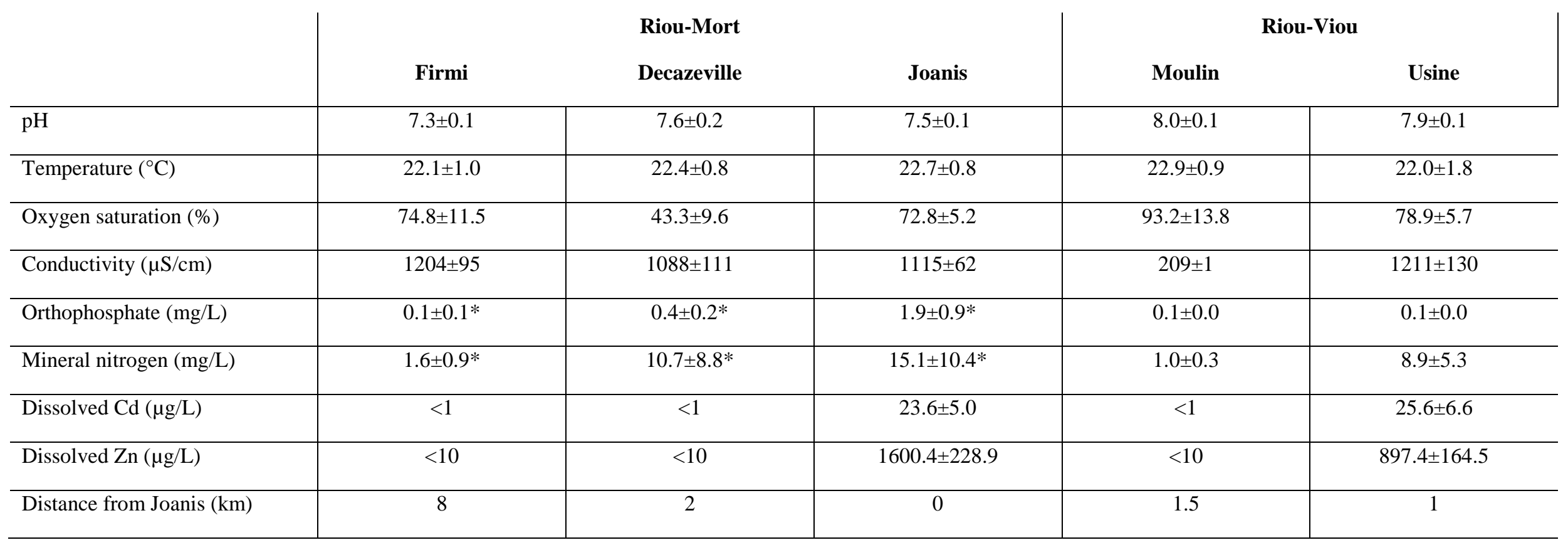

The table illustrates the gradient in water quality degradation from Firmi to downstream sites: the nutrient inputs from Decazeville are cumulated with metal contamination in Joanis. In Decazeville, dissolved oxygen as well as conductivity decrease, and then recover the levels of Firmi at Joanis. 